\title{
Progress and development on multi-parameters remote sensing application in earthquake monitoring in China
}

\author{
Xuhui Shen $\cdot$ Xuemin Zhang $\cdot$ Shunying Hong $\cdot$ \\ Feng Jing $\cdot$ Shufan Zhao
}

Received: 6 January 2013/Accepted: 2 December 2013/Published online: 31 December 2013

(C) The Seismological Society of China, Institute of Geophysics, China Earthquake Administration and Springer-Verlag Berlin Heidelberg 2013

\begin{abstract}
In this paper, the progress and development on remote sensing technology applied in earthquake monitoring research are summarized, such as differential interference synthetic aperture radar (D-InSAR), infrared remote sensing, and seismo-ionospheric detecting. Many new monitoring data in this domain have been used, and new data processing methods have been developed to obtain high-precision images about crustal deformation, outgoing longwave radiation (OLR), surface latent heat flux (SLHF), and ionospheric parameters. The development in monitoring technology and data processing technique largely enriches earthquake research information and provides new tools for earthquake stereoscope monitoring system, especially on the space part. Finally, new developing trend in this area was introduced, and some key problems in future work were pointed out.
\end{abstract}

Keywords Remote sensing monitoring - D-InSAR . Infrared remote sensing $\cdot$ Seismo-ionospheric detecting

\section{Introduction}

Earthquake Science is an observational science, so rich observing information is a key factor in earthquake research. Earth observation by space technology is unmatchable for ground-based detecting technology, which has the features of global observation, high-dynamic-range, all-time, unlimited by natural conditions on ground, and can increase greatly checking chance of earthquake events and

X. Shen $\cdot$ X. Zhang $(\bowtie) \cdot S$. Hong $\cdot$ F. Jing $\cdot$ S. Zhao

Institute of Earthquake Science, China Earthquake

Administration, Beijing 100036, China

e-mail: zhangxm96@126.com enrich the information content of earthquake precursors. These advantages can help to test effectively and develop methods and theory on earthquake prediction, to improve the understanding the laws in earthquake preparation, occurrence, and development. Remote sensing monitoring has developed into a new hotspot in earthquake monitoring and prediction research (Gokhberg et al. 1983; Massonnet et al. 1993; Parrot 1995; Hayakawa 2001; Tronin et al. 2002; Ouzounov and Freund 2004; Shen et al. 2007).

\section{General situation of remote sensing technology application in earthquake science in China}

The application research begins from 1970s, of the earth observation technology by satellite in earthquake prevention and disaster mitigation. By using mobile satellite system (MSS) satellite images of USA at that time, national investigation on active structures was carried out, and The Album of typical Satellite Imagery of Active structures of China (1982) with 1:4,000,000 was edited since 1978. Taken account of the requirements of development in earthquake prevention and disaster mitigation, studies on rapid earthquake disaster assessment methods started since later stage of 1980 s by satellite and aerial remote sensing technologies. In 1988, West Yunnan Earthquake Test Site took the lead in GPS observation experiment, and then satellite thermal infrared earthquake monitoring technology and technique research were developed gradually since 1990 (Qiang et al. 1990).

Since the Tenth Five-Year National Science and Technology Development Program in China (2001-2005), in order to the implementation of related national research plans and major scientific projects, earthquake remote sensing application research and application system construction were paid high-level attention, deployed, and developed 


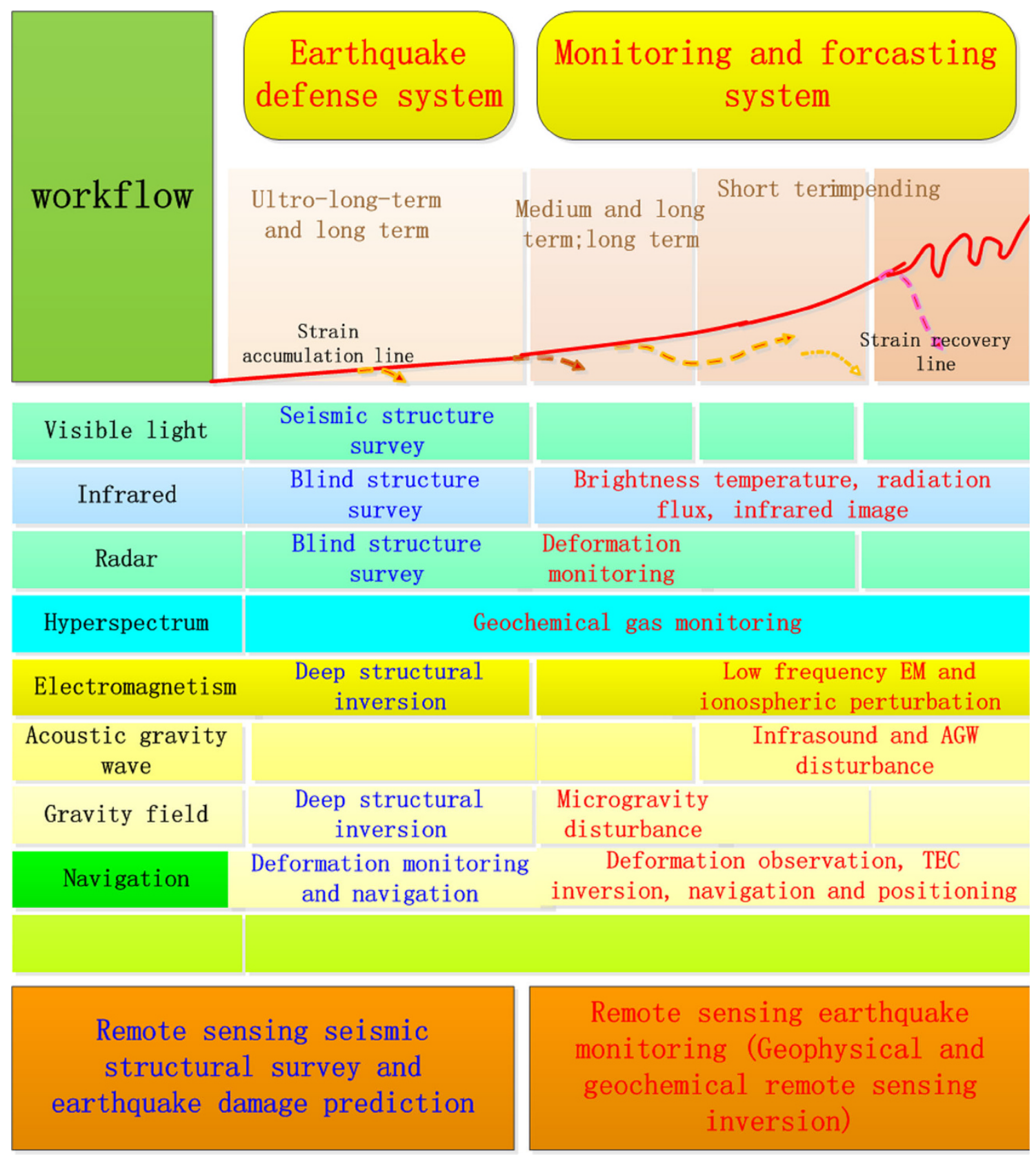

Fig. 1 The main application field of space technology in earthquake prevention and disaster mitigation

systematically and comprehensively. Focused on construction requirements in earthquake monitoring capability, the key techniques in earthquake monitoring and prediction were developed systematically and achieved remarkable progress by satellite electromagnetism, satellite infrared, and InSAR technology. The statistical research was promoted on historical earthquakes, and the space precursory characters were summarized initially in electromagnetism, infrared, deformation, and other information, which laid the foundation for gradually promoting the practical use. On the basis of these works, argumentation on the first space-based platform has been finished in earthquake stereoscope observation system in China, and integrated earthquake remote sensing application system has been designed comprehensively.

At present, space technology has been applied in all works of earthquake prevention and disaster mitigation (Fig. 1). Remote sensing geology has become the basic tool for earthquake research, and satellite technologies represented by satellite infrared, InSAR, and global navigation satellite system (GNSS) have played significant role in earthquake monitoring and prediction. Relied on high-resolution optical remote sensing, the capability on earthquake disaster 
assessment has been improved greatly. As, GNSS and satellite communication serve as the fundamental guarantee in earthquake emergency response and field seismic work.

\section{Earthquake-related deformation monitoring by SAR remote sensing}

\subsection{Co-seismic deformation measurement by D-InSAR}

The D-InSAR technique offers new possibilities to observe and study coseismic and postseismic deformation and even inter-seismic deformation. The main advantage of D-InSAR for studying coseismic deformation is the low cost and high spatial resolution of the observations. And it is often the only measurement available for the coseismic deformation field in the Tibetan Plateau where no conventional geodetic measurement networks exist.

The first earthquake studies using D-InSAR were on the 1992 Landers $M_{\mathrm{w}} 7.3$ earthquake obtained by the Massonnet et al. (1993) and Zebker et al. (1994), and these studies clearly demonstrated the power of this technique to observe coseismic deformation. Many studies followed and some authors have made important contributions to earthquake science. D-InSAR measurements have also allowed researchers to estimate the fault slip distribution of large earthquake, for example, the Jonsson et al. (2002) had inversed the seismic slip distribution of the 1999 Hector Mine earthquake, and Shen et al. (2009) obtain the slip distribution and rupture feature of the 2008 Wenchuan earthquake by the D-InSAR and GPS measurement. The D-InSAR technique has been used in many other earthquakes which happed in China, such as the 1997 Manyi $M_{\mathrm{w}} 7.6$ earthquake by Shan and Zhang (2006), Xu and Wen (2008) and Sun et al. (2007a), the 1998 Zhangbei-Shangyi $M_{\mathrm{s}} 6.2$ earthquake by Shan et al. (2003), the 2001 Western Kunlunshan $M_{\mathrm{w}} 7.9$ earthquake by Shan et al.(2004) and Wang and his co-workers (2008), the 2008 Gaizhe $M_{\mathrm{w}} 6.4$ earthquake by Sun et al. (2008) and Feng et al. (2009), the 2008 Yutian $M_{\mathrm{w}} 7.1$ earthquake by Hong et al. (2010a, b) and Zhang et al. (2011), the 2008 Dangxiong $M_{\mathrm{w}} 6.3$ earthquake by Feng et al. (2010) and Sun et al. (2011), and 2010 Yushu $M_{\mathrm{w}} 6.9$ earthquake by $\mathrm{Hu}$ et al. (2012) and Qu et al. (2013).

\subsection{The measurement of small crustal deformation}

After the deformation field of Landers $M_{\mathrm{w}} 7.3$ earthquake obtained by the Massonnet et al. (1993) by European remote sensing satellite (ERS-1) data, the D-InSAR technology caused great concern of the international seismological community. Due to the atmospheric effects, digital elevation model (DEM) error, incoherence, etc., the measurement accuracy of D-InSAR can only achieve centimeter- level, and cannot be suitable for long-term and slow crustal deformation monitoring. In order to overcome the error sources of the conventional D-InSAR, Ferretti et al. (2001) firstly developed the Permanent Scatters (PS) measurement method, which can achieve mm-level accuracy. Afterward, the Small Baseline InSAR (SBAS InSAR), Multi-temporal InSAR (MT-InSAR), Multicale InSAR Time Series (MInTS), and Distributed Scatterers (DS) that was developed based on PS method, have obtained the success of small crustal deformation monitoring (Hooper 2008; Ferretti et al. 2011; Hetland et al. 2012).

Supported by the GPS-2 Project and the Eleventh FiveYear Science and Technology Development Program of China (2006-2010), China Earthquake Administration has a system launched PS/CR-InSAR technology research work. At present, we have built about 106 artificial Corner Reflectors(CR) around the Haiyuan fault, Liupanshan fault, and north edge of XiqinLing fault, which in the northern section of north-south seismic belt; and also built dozens of CR in the Yangbajing basin, Yanhuai basin northwest of Beijing, and Lijiang basin. And by the deformation monitoring, we found: eastern of Haiyuan fault displays a left lateral slip rate about 6-7 mm/a, the average cumulated displacement of these points in 2003-2009 is about $4.2 \mathrm{~cm}$, which is roughly in agreement with that from GPS measurements and geological investigations (Qu et al.2011); the land subsidence in the areas of geothermal wells is up to $25 \mathrm{~mm} / \mathrm{a}$, while the subsidence in the basin is less than $1 \mathrm{~mm} / \mathrm{a}$ ( $\mathrm{Li}$ et al. 2012).

\subsection{D deformation solving methods}

One of the limitations of InSAR is that it only measures one component of the surface deformation-in the satellite's line of sight (LOS), but not the real surface deformation in the west-east, north-south, and vertical directions, and this question is named "LOS Ambiguity". It is important for overcoming this problem to transfer the LOS deformation to real surface 3D deformation. By the Multi-LOS InSAR measurement, combined with deformation simulation, Offset-tracking and GPS technology, Hong et al. (2010a, b) had built up a 3D deformation solving model to obtain the 3D deformation field of 9th and 16th January 2008 Gaizhe $M_{\mathrm{w}} 6.4$ and $M_{\mathrm{w}} 5.9$ double earthquake, 21st March 2008 Yutian $M_{\mathrm{w}} 7.1$ earthquake and 26th December 2003 Bam $M_{\mathrm{w}} 6.9$ earthquake. The analysis of 3D deformation shows that the $M_{\mathrm{w}} 6.4$ Gaizhe main shock was mainly ruptured by normal and left-lateral striking with a little rotation to east, and Gaizhe $M_{\mathrm{w}} 5.9$ after shock was mainly ruptured by normal faulting with a little right-lateral striking (Fig. 2); Yutian earthquake is mainly ruptured by normal faulting and left-lateral striking, and spatial distribution of the threesegment seismic rupture is featured by left step en echelon; the Bam earthquake was ruptured mainly by right-lateral 


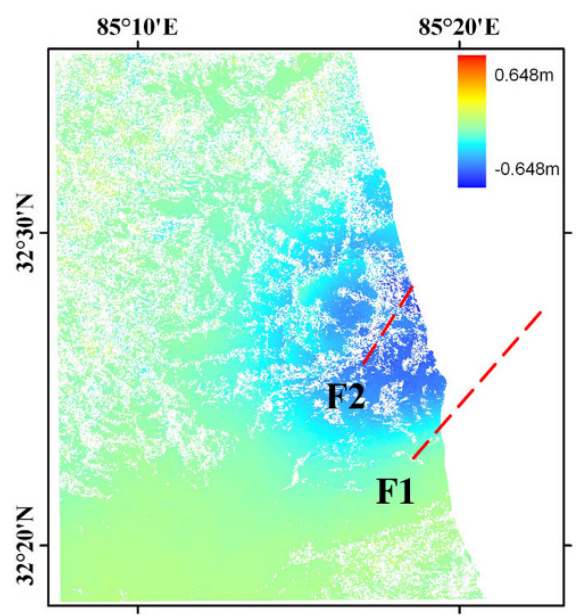

$(\mathrm{dU})$

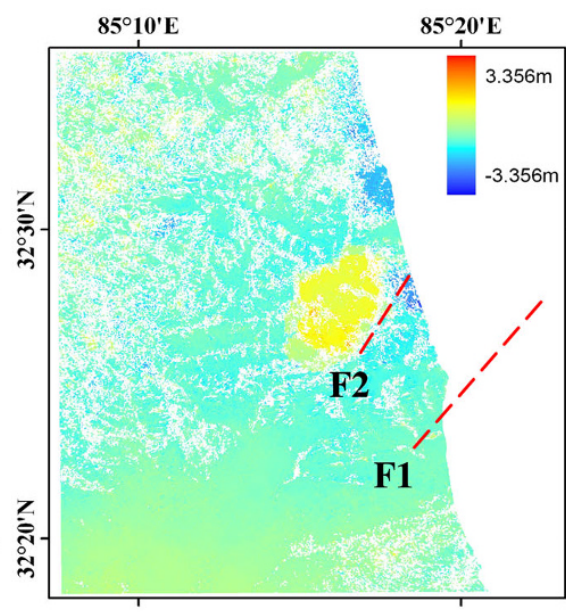

$(\mathrm{dN})$

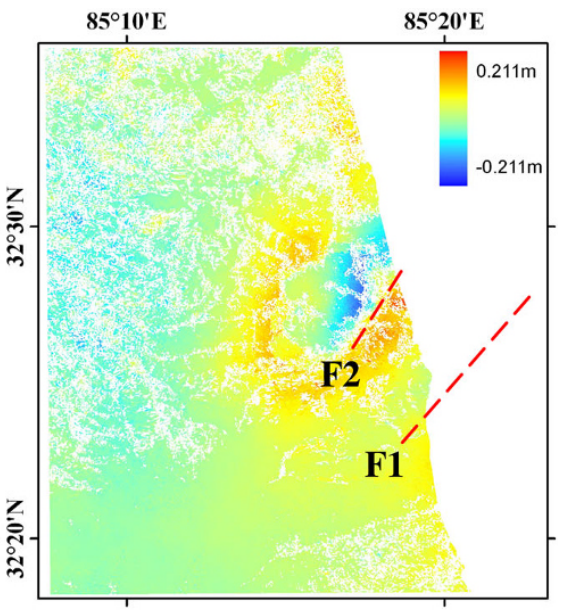

$(\mathrm{dE})$

Fig. 2 3D deformation field of Gaize earthquake (by Hong et al. 2010a, b) (dU, dN, dE are respectively referring to the up, north, east orientation deformation; the movement toward upward, northern, and eastern is positive deformation, and toward downward, southern, and western are negative deformation; the red dashed-lines are the seismic faults F1 and F2)

striking mechanism, with a little left-lateral horizontal rotation in the east-west direction.

\subsection{Offset-tracking and MAI measurement}

Due to the serious incoherent of time and space in the dense vegetation and mountain area and the unwrapped of the interferometer phase in the zone of extremely deformation gradient around seismic rupture, interferometry method is often unable to obtain the co-seismic deformation information of meizoseismal area. Offset-tracking measurement was proposed to make up this deficiency (Michel and Avouac 1999), which can obtain the two-dimensional deformation of Slant Range and Azimuth direction. The advantages of this method are fully reflected in the co-seismic deformation field extraction of the 12th May, 2008 Wenchuan $M_{\mathrm{w}} 7.9$ earthquake (Liu 2010), when the InSAR measurement cannot get the deformation information near the seismic ruptures. And, the Multiple Aperture Interferometry (MAI) technology proposed by the Bechor and Zebker (2006) can also effectively extract the two-dimension deformation field of Slant Range and Azimuth direction. The Sun et al. (2008) and Hu et al. (2012) have using the MAI technology to obtain the two-dimension cosesimic deformation fields, respectively, in the 2008 Gaize earthquake and 2010 Yushu earthquake.

\section{Earthquake precursor monitoring technology using infrared remote sensing}

The First application of thermal images in earthquake was carried out in 80th for Middle Asia by Gorny et al. (1988).
The most outstanding IR anomalies are represented by $M 7.2$ Gazli earthquake March 19, 1984. The anomalies appear 1 week before this earthquake, and the area of anomaly exceeds $100000 \mathrm{~km}^{2}$. After that, the satellite thermal infrared anomaly related to earthquake has been demonstrated by many researchers, and Chinese scientists are important research team. Xu et al. (1993), Deng et al. (1997), and Qiang et al. $(1990,1997)$ make preliminary studies on the mechanism of earthquake infrared anomalies. The change of rock stress or atmospheric electric field, and the greenhouse effect are possible causes for thermal anomalies. Some case studies have been carried out by Liu and Kang (2005), Chen et al. (2006), Qu et al. (2006), Liu et al. (2007a, b), Kang (2008), and Jing et al. (2009). According to the data used, these cases studies can be classified into two categories: multi-parameter and multi-band.

\subsection{Multi-parameter infrared variation related to earthquakes}

Many kinds of infrared physics parameters can be used to study the anomalies associated with earthquakes, such as brightness temperature (BT), outgoing longwave radiation (OLR), and surface latent heat flux (SLHF). BT is defined as the temperature of a blackbody that emits the same intensity as measured. OLR is the emission to space of terrestrial radiation from the top of the earth's atmosphere and controlled by the temperature of the earth and the atmosphere above it, the water vapors in the atmosphere, and the clouds. SLHF is an atmospheric parameter, which can describe the heat released by phase changes and dependent on meteorological parameters such as surface 
temperature, relative humidity, wind speed, etc. The recent studies have demonstrated that these parameters may be as abnormal indicators as seismic precursor (Liu et al. 2007a, b; Xiong et al. 2010; Qin et al. 2011, 2012; Wu et al. 2012a; Jing et al. 2013).

Earthquake preparation is a complex process, it is difficult to identify anomaly just according to one parameter. The process of earthquake preparation is accompanied by the exchanges of mass and energy, which can change the energy budget in the earth-atmosphere system on the seismogenic zone. BT, OLR, and SLHF can reflect this variation. This theory may provide important support for the comprehensive analysis of infrared remote sensing multi-parameter in earthquake study. Therefore, infrared multi-parameter comprehensive study has important significance in the infrared seismic monitoring.

Different data processing methods have been proposed according to different parameters, such as standard deviation (STD) threshold, power spectrum estimation, backgrounddeleted, which can be found in the related literatures (Jing et al. 2010; Guo et al. 2010; Li et al. 2010). Supported by the National Key Technology R\&D Program of China, Over one hundred seismic cases have been analyzed using infrared multi-parameter. Taking Wenchuan earthquake, for example, BT, OLR, and SLHF show obvious variation (Fig. 3) for several days before this event. Since the physical meanings of these parameters are different, their respective anomalies performances on spatial and temporal characteristics are different. The area of BT anomalies is the largest than OLR and SLHF, and the position of OLR and SLHF anomalies is closer to the epicenter of earthquake than BT.

And according to the result of over one hundred seismic cases, the variation characteristics of these parameters prior to the earthquakes have been summarized. Approximately, $50 \%$ earthquakes of the magnitude greater than 5.0 appear abnormal variation on these parameters. The variation characteristics of BT, OLR, and SLHF related to earthquake can be seen in the Table 1. It is greatly similar and synchronous for infrared multi-parameter in the process of earthquake preparation, e.g., the anomalies mostly appeared in two weeks prior to earthquakes; the location of seismic anomalies was different for each parameter. BT anomalies usually isolated and have a large area of distribution; OLR and SLHF are near the epicenter and always distribute along the seismogenic fault; the infrared anomalies are more likely to be detected in earthquakes that magnitude greater than 6.0.

LCA (Lithosphere-Coversphere-Atmosphere) coupling model has been proposed by China scientist according to analyzing the variation of multi-parameter(including outgoing longwave radiation, surface latent heat flux, thermal infrared radiation, diurnal temperature range, atmospheric temperature, and skin temperature) before some major earthquakes (Wu et al. 2012a, b). This model can explain the quasi-synchronism and geo-consistency of different parameters in different spheres, which will help us to better understand the mechanism of earthquake infrared anomalies variation.

Table 1 Features of Infrared Multi-parameter variation related to earthquakes

\begin{tabular}{|c|c|c|c|c|}
\hline \multirow[t]{2}{*}{ Parameter } & \multicolumn{3}{|c|}{ Characteristics } & \multirow{2}{*}{$\begin{array}{l}\text { Reflect } \\
\text { capacity }\end{array}$} \\
\hline & Time & Space & Magnitude & \\
\hline BT & $\begin{array}{l}\text { Most in } \\
15 \text { days }\end{array}$ & $\begin{array}{l}\text { Isolated, } \\
\text { always not } \\
\text { in the } \\
\text { epicenter }\end{array}$ & $\begin{array}{l}1-3(\mathrm{~K} \\
\text { threshold) }\end{array}$ & $\begin{array}{l}>M 6.0 \\
\text { for } \\
\text { better }\end{array}$ \\
\hline OLR & $\begin{array}{l}\text { Several } \\
\text { days to } \\
\text { few } \\
\text { months }\end{array}$ & Near the fault & $\begin{array}{r}1.5-3 \text { (STD } \\
\text { threshold) }\end{array}$ & $\begin{array}{l}>M 6.0 \\
\text { for } \\
\text { better }\end{array}$ \\
\hline SLHF & $\begin{array}{l}\text { Most in } \\
2 \text { weeks }\end{array}$ & $\begin{array}{l}\text { Moving } \\
\text { toward to } \\
\text { the } \\
\text { epicenter }\end{array}$ & $\begin{array}{l}>90 \mathrm{~W} / \mathrm{m}^{2} \\
\text { (difference } \\
\text { from } \\
\text { background) }\end{array}$ & $\begin{array}{l}>M 6.0 \\
\text { for } \\
\text { better }\end{array}$ \\
\hline
\end{tabular}

20080508

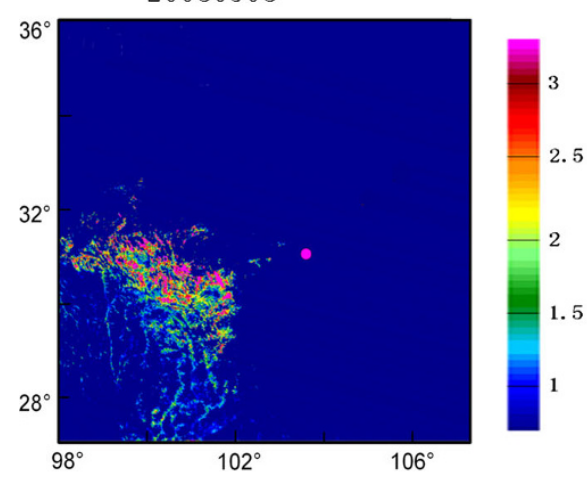

20080510

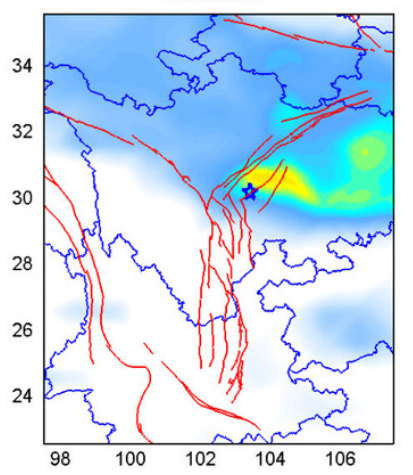

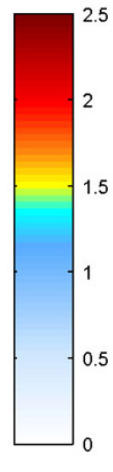

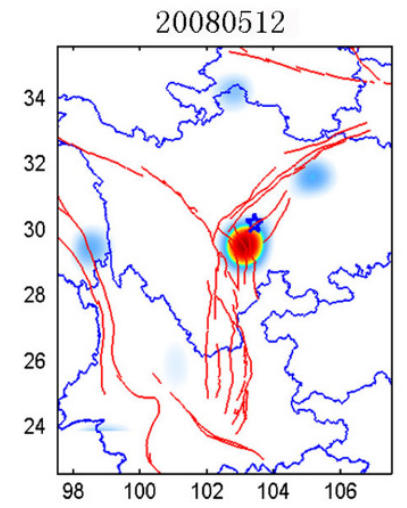

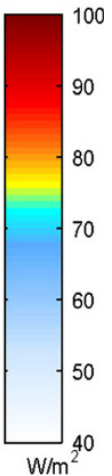

Fig. 3 Multi-parameter variation prior to Wenchuan earthquake (Wen 2011; Jing et al. 2013) (left BT, middle OLR, right SLHF. Epicenter is marked with star or point, active faults with red lines) 


\subsection{Multi-band infrared variation related} to earthquakes

At present, earthquake infrared anomalies research mainly concentrated in two infrared bands, far-infrared $(8-12 \mu \mathrm{m})$ and longwave infrared $(4-50 \mu \mathrm{m})$. Outgoing longwave radiation data have been applied in seismologic consideration of China earthquake networks center, and far-infrared data are also the important information for carrying out earthquake prediction in some provincial earthquake bureau.

In recent years, mid-infrared (3-5 $\mu \mathrm{m}$ ) has been exploring the potential applications in order to study multi-band infrared variation related to earthquakes. It has been found that mid-infrared, far-infrared, and long-wave infrared can play a role in seismic infrared radiation anomalies detection. But cloud detection and removing must be carried out before seismic information extraction, because mid-infrared and far-infrared radiations are affected by clouds. So it is difficult to obtain infrared brightness temperature variation in continuous time. And outgoing longwave radiation data reflect the radiation on the top of the clouds and conducive to obtain continuous radiation variation, which have great significance to study short-term and impending earthquake precursor. Besides, microwave radiation seismic anomalies also are found in some earthquakes by China scientist (Liu et al. 2012). So the comprehensive analysis on radiation information derived from different wavebands related to earthquakes is an important developing trend in future.

\section{Seismo-ionospheric detection technology}

With the development of ionospheric detecting technology and accumulation of numerous earthquake cases, remarkable ionospheric disturbances have been found around some large earthquakes. Seismo-ionospheric signals receive the world attention due to its typical short-term precursory feature, and then satellite electromagnetic detection technology has got rapid development. Although ground-based seismo-electromagnetic precursor detection has continued a few 10 years in China, seismo-ionospheric research started late (Ding et al. 2004; Wu et al. 2005) and witnessed rapid growth especially after the plan of China seismo-electromagnetic satellite (Shen et al. 2011). At present, the main technical tools on space ionosphere detection include ground-based vertical ionosonde/slant ionosonde, the total electron content (TEC) by inversion of global position system (GPS) observation, occultation events, in-situ satellite observation, and so on.

\subsection{Research on seismo-ionosphere coupling mechanism}

Abroad scientists found that the electromagnetic signals, chemical materials, ground waves produced during the earthquake preparation processes mainly propagate and cause perturbations of electromagnetic field and plasma parameters in ionosphere by three ways: electromagnetic wave propagation, acoustic gravity wave propagation, direct current (DC) electric field coupling (Molchanov et al. 1995; Pulinets et al. 1994; Sorokin et al. 2001). In order to explain the anomalous phenomena in ionosphere related to earthquakes, Chinese expert has also carried out corresponding study on theoretical simulation.

Zhang et al. (2009a) analyzed the behavior of extremely low frequency/super low frequency (ELF/SLF) electromagnetic waves in atmosphere and ionosphere with the variation horizontal distance, altitude, frequency, and depth of electric dipole. Wang et al. (2009) deduced the spherical harmonic expression of electromagnetic field produced underground, aboveground and in ionosphere from underground SLF/ELF horizontal electric dipole by regarding the ground layers and ionosphere as spherical uniform sharp boundary mediums. Zhao et al. (2010) developed the full-wave modeling of transionospheric propagation of very low frequency (VLF) waves which was applied to calculate the electromagnetic field in the stratified ionosphere for ground-based dipole transmitters and compared to observation. The simulation results coincide with the observations, which illustrate the reliability of the propagation model of electromagnetic waves (Shen et al. 2011).

The simulation on traveling ionospheric disturbances was only done by linear transfer function (Sun et al. 2006, 2007b). Lu (2008) built 2D numerical model of acoustic gravity wave propagation under polar coordinates. The results show that responding perturbations in ionosphere occur after the excitation of gravity wave, and the amplitude amplifies with the increase of altitude. Based on compressible inviscid 2D gas, we simulate the nonlinear propagation process of acoustic gravity waves. Figure 4 shows that the wave packet changes significantly during the propagation process, with the related disturbance wave velocity exponentially rising with the increase of height. The wave packet moves to the upper right continuously.

\subsection{Data processing techniques of electromagnetic satellite observation}

The space ionospheric variation is influenced mainly by solar activity, in which the daily, seasonal, and annual variations are all related to that. Multi-parameters in ionosphere will change intensively in large scale under the effects of severe space weather events like sun coronal mass ejection, magnetic storms, etc. Seismic activity and volcano eruption are just weak factors to affect the ionosphere. Their excitation sources are formed underground or on the surface, and their intensity will damp to some extent when propagating to the ionosphere, so they become the weak signals under strong electromagnetic 

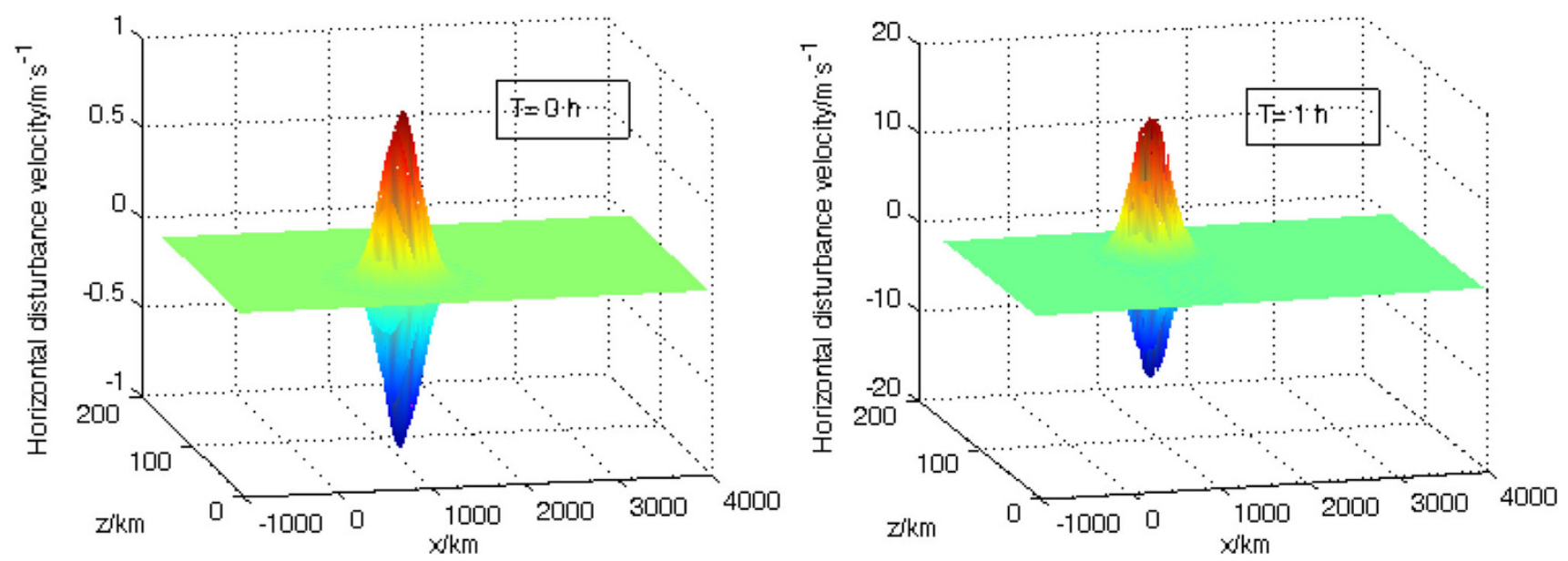

Fig. 4 Horizontal movement of nonlinear gravity wave packet with time (left $T=0 \mathrm{~h}$, right $T=1 \mathrm{~h})$

background in ionosphere. When the ionospheric detecting data by satellite are employed in earthquake research, the distinguishing methods on anomalies are crucial besides deleting out the routine disturbances from instruments.

On the basis of widespread application and continuously validation, some kinds of anomaly extraction techniques have been built, and they play an important role in case studies (Zhang et al. 2009b; Yang et al. 2011). The space electromagnetic observation has four dimensional variation features due to the flying mode of satellite. The key point in anomaly extraction is to construct different extraction techniques in accordance with different observational data, based on clear understanding on background information. So far the widely used methods can be concluded as following, such as Time Series Analysis to construct the long time sequence in a studied region by accumulating the observational data average or median for a certain period of time and space scale (Zhang et al. 2009b); space-time resampling methods for the global or regional spatial observation data (Liu et al. 2013); wave vector analysis to get the propagation feature of electromagnetic wave ( $\mathrm{Yu}$ et al. 2010); and computerized ionospheric tomography(CIT) aiming at the profile data in ionosphere by GPS TEC, occultation, and tri-frequency beacon (Yang et al. 2011).

\subsection{Statistical analysis on electromagnetic satellite data and seismo-ionospheric characteristics}

Owing to the certain randomness and occasionality in case study, all kinds of observational tools and anomaly analytical techniques need to validate by accumulation of numerous earthquake cases and statistical analysis, to estimate the correlation between detecting technology and earthquakes. The accumulation of large amount of data makes it possible to do the statistical analysis between ionospheric perturbations and earthquakes. In recent years, the seismo-ionospheric statistical analysis has been widely carried out about earthquakes over China and the world.

Xu et al. (2012) analyzed the critical frequency of F2 layer (foF2) related to 14 large earthquakes in China mainland, and they found that ionospheric anomalies occurred before $85.7 \%$ earthquakes, mostly at 11:00-17:00 LT in 7 days before the earthquakes. Le et al. (2011) performed statistical analysis on global $736 M \geq 6.0$ earthquakes during 2002-2010 by GPS TEC. Their results demonstrate that GPS TEC varied more intensively before the earthquake with bigger magnitude, shallower focus, and closer time. Yao et al. (2012) studied the global earthquakes with $M \geq 7.0$ in 2010, and they found that GPS TEC anomalies occurred 0-2 days before the earthquakes, concentrating at 12:00-20:00. Zhu et al. (2010) did statistical research on TEC around 50 earthquakes with $M_{\mathrm{s}} \geq 7.0$ since 2007 , which demonstrated that obvious ionospheric perturbations occurred before $94 \%$ cases. Positive and negative anomalies all have been detected, and negative anomalies always occurred 1 week before earthquakes, while positive ones had no evident function relation with the occurrence time. Zhang et al. (2012) analyzed the ionospheric perturbations in static electric field data observed by detection of electro-magnetic emissions transmitted from earthquake regions (DEMETER) satellite around global earthquakes larger than 7.0 during 2005-2010. Their results revealed that interplate earthquakes can excite the ionospheric disturbances more easily. The power spectrum of electric field increased to 1-2 orders of magnitude, and the anomalies gradually concentrated to the epicenter when the earthquake approached. $\mathrm{He}$ et al. (2011) studied DEMETER data around 7000 $M \geq 5.0$ earthquakes taking place in 2006-2009. Their paper exhibited that the electron density was enhanced both over southern and northern hemisphere, but anomaly center was located at north to the epicenter over northern hemisphere and at south over southern hemisphere. The disturbances were 
Table 2 Features of electromagnetic variations related to earthquakes in ionosphere

\begin{tabular}{lllll}
\hline Parameter & Characteristics & & & $\begin{array}{c}\text { Correspondent ratio to } \\
M_{\mathrm{s}} \geq 7.0 \text { earthquakes (\%) }\end{array}$ \\
\cline { 2 - 5 } & Time & Space & Amplitude & 46 \\
\hline In-situ electric field & 3 days & $\Delta$ lat $\leq 10^{\circ}$ & Enhancement by 1-2 order of magnitude & 32 \\
In-situ plasma parameters & A week & $\leq 2,000 \mathrm{~km}$ & $20-100 \%$ & 85.7 \\
foF2 & A week & $\leq 1,000 \mathrm{~km}$ & Beyond quartile & $60-94$ \\
GPS TEC & A week-2 days & $\leq 2,000 \mathrm{~km}$ & Beyond quartile & \\
\hline
\end{tabular}

more intensive around oceanic earthquakes than inland cases. The anomalous amplitude became larger with the increase of earthquake magnitude, but being less with deeper focal depth. Table 2 summarized the anomaly characteristics in space, time, and magnitude about different electromagnetic parameters, which illustrate that ionospheric electromagnetic anomalies have significant imminent feature relative to the earthquake, but distribute in relative larger scales in ionosphere.

Until now most researches illustrate positive relationship between ionospheric disturbances and seismic activities, especially the temporal relationship. However, the studies in China lay particular stress on seismic events and focus less on research of nonseismic time segments and the occurring probability of similar signals in other regions. Full spatial scanning to same kinds of anomalies as those related to earthquakes needs further development in future studies.

\section{Trends and prospects on RS application in earthquake science}

In past years, the whole world had been continuously attacked by a few giant earthquakes even with magnitude larger than 9, and population, economy, and society suffer huge losses. Stimulated by these unexpectedly great disasters, scientists enhanced the introspection and summary on earthquake monitoring and forecasting ways, and on the other hand, they paid more attention on the multisphere interaction with the rapid development of space technology. By using the advantages as all-time, highdynamic, and global observation in satellite remote sensing technology to develop, the space-based earthquake observational system has become a major trend of technological development in earthquake monitoring and prediction.

(1) More emphasis on the construction of the space segment of China earthquake stereoscope observation system

The first Chinese seismo-electromagnetic monitoring satellite is viewed as a test satellite with clear application prospect in monitoring and forecasting field, equipped with the capability of in-situ observation on plasma parameters and ionospheric structural tomography. At the moment, the first electromagnetic satellite has entered into the engineering development phase and is due to be launched around the end of 2015 and operation for 5 years together with existing ground-based observational network.

To cope with the overall planning of national civil space remote sensing system, on the basis of developing electromagnetic monitoring test satellite, the satellite-based earthquake monitoring system will be constructed gradually by satellite detecting information, which including following 3 sub-systems: (1) earthquake deformation observation system and application research combined InSAR, satellite gravity and GNSS with the goal of mediumand long-term earthquake monitoring and forecasting; (2) infrared observation and technical system and application research with the goal of medium- and short-term earthquake monitoring and forecasting; (3) satellite-based electromagnetic observation and technical system and application system with the goal of short-term and imminent earthquake monitoring.

(2) Much attention on geophysical remote sensing detection and inversion techniques

For a long time, space technology and remote sensing community have paid close attention on imaging remote sensing technologies, keeping improve the corresponding spatial, temporal, and spectral resolution. So far the imaging remote information has played significant roles in territorial resources surveys, natural disasters prevention and reduction, ecological environment monitoring, and many other fields, evolving several superior application fields such as geological remote sensing, disaster remote sensing, and so on.

The development of remote sensing technology also spurred the occurrence of earth system science. However, it has been the hotspot in scientific community that how to implement the detection and observation on the whole earth system based on advanced detecting technologies. Essentially, electromagnetic field and gravitational field, as the natural media connecting the multi layers of the earth, have good transport link in each sphere of the earth's 
system, and representation capability of their correlations, consequently becoming the important tools in detecting the interaction among multi spheres in the earth system by remote sensing technologies.

Taking this opportunity, geophysical remote sensing detection and inversion technique research focused on electromagnetic field and gravity field have been paid more and more attention by international academia. The development of electromagnetic satellite and gravitational satellite is becoming new hotspots in current international remote sensing technology field. Since 2000, several space power countries like America, Russia, European Union (EU), etc. have developed some specialized electromagnetic and gravitational satellites such as DEMETER, gravity field and steadystate ocean circulation explorer (GOCE), gravity recovery and climate experiment (GRACE), and so on, while the electromagnetic satellite constellation SWARM is going to be launched. Based on these specialized satellites' observing information, some researches have come to academic hotspots, for example, the earth ionosphere and atmosphere tomography combined with extended application of GNSS, the earth interior structure detection and inversion techniques based on satellite observation, statistical analysis of global earthquakes, and earthquake science research upon the results of geophysical remote sensing detection.

(3) Imminent major scientific projects by international cooperation

So far, China Earthquake-related Satellite Plan has undergone 10 years progress. From systematically learning the advanced foreign experiences, we effectively push forward all the researches, which powerfully guarantee the implement of China Earthquake Satellite Plan. As extensive international cooperation and communication has been built by taking part in bilateral and multilateral academic communication activities. With the development of the first electromagnetic satellite plan in China, the International Academy of Astronautics (IAA) organized two workgroups of International Global Monitoring Aerospace System (IGMASS) and School for Global Education and Innovation (SGEI) facing giant natural disaster monitoring and early warning, to push through coordinated application of global resources. ESA (European Space Agency) collaborated with Russian space agency, and they proposed their earthquake prediction research project PRE-EARTHQUAKES, in which they planned to develop and offer to the international scientific community an integration platform (PEG) where independent observations and new data analysis methodologies devoted to the research on/of earthquake precursors can be collected and cross-validated.

Acknowledgments This paper is the common achievements of implementing team in satellite plan of China Earthquake Administration (CEA). Besides the authors named in the paper, many persons have been involved in this work, including experts from Institute of Geology, Institute of Crustal Dynamics, Institute of Seismology, Institute of Geophysics, China Earthquake Network Center, Lanzhou Institute of Seismology, and all the colleagues of Lab. of Earthquake Observation from Space in Institute of Earthquake Science, CEA. It is supported by the International Science and Technology Cooperation Program of China (2010DFB20190), the Key Project of Earthquake Science (201008007).

\section{References}

Bechor NBD, Zebker HA (2006) Measuring two-dimensional movements using a single InSAR pair. Geophys Res Lett 33:L16311. doi:10.1029/2006GL026883

Chen MH, Deng ZH, Yang ZZ, Ma XJ (2006) Surface latent heat flux anomalies prior to the Indonesia $M_{\mathrm{w}} 9.0$ earthquake of 2004. Chin Sci Bull 51(8):1010-1013 (in Chinese with English abstract)

Deng MD, Geng NG, Cui CY, Zhi YQ, Fan ZF, Ji QQ (1997) The study on the variation of thermal state of rocks caused by the variation of stress state of rocks. Earthq Res Chin 13(2):179-185 (in Chinese with English abstract)

Ding JH, Suo YC, Yu SR, Xiao WJ (2004) Comparison study on short-term anomalies of ionosphere and geomagnetic field before Kunlunshan $M_{\mathrm{s}} 8.1$ earthquake. Earthquake 24(1):106-111 (in Chinese with English abstract)

Feng WP, Xu LS, Xu ZH, Li ZH, Li CL, Zhao H (2009) Source parameters of the 2008 Gêrzê $M_{\mathrm{w}} 6.4$ and $M_{\mathrm{w}} 5.9$ earthquakes from InSAR measurements. Chin J Geophys 52(4):983-993. doi:10.3969/j.issn.0001-5733.2009.04.015 (in Chinese with English abstract)

Feng WP, Xu LS, Li ZH (2010) Fault parameters of the October 2008 Damxung $M_{\mathrm{w}} 6.3$ earthquake from InSAR inversion and its tectonic implication. Chin J Geophys 53(5):1134-1142. doi:10. 3969/j.issn.0001-5733.2010.05 (in Chinese with English abstract)

Ferretti A, Claudio P, Fabio R (2001) Permanent scatterers in SAR interferometry. IEEE Trans Geosci Remote Sens 39(1):8-20

Ferretti A, Fumagalli A, Novali F, Prati C, Rocca F, Rucci A (2011) A new algorithm for processing interferometric data-stacks: SqueeSAR. IEEE Trans Geosci Remote Sens 49(9):3460-3470. doi:10. 1109/TGRS.2011.2124465

Gokhberg MB, Pilipenko VA, Pokhotelov OA (1983) Seismic precursors in the ionosphere. Izvestiya Earth Phys 19:762-765

Gorny VI, Salman AG, Tronin AA (1988) The Earth's outgoing IR radiation as an indicator of seismic activity. Proc Acad Sci USSR 301:67-69

Guo X, Zhang YS, Zhong MJ, Shen WR, Wei CX (2010) Variation characteristics of OLR for the Wenchuan earthquake. Chin J Geophys 53(11):2688-2695 (in Chinese with English abstract)

Hayakawa M (2001) NASDAs earthquake remote sensing frontier research: seismoelectromagnetic phenomena in the lithosphere, atmosphere and ionosphere, final report, University of ElectroCommunications

He Y, Yang D, Qian J, Parrot M (2011) Response of the ionospheric electron density to different types of seismic events. Nat Hazards Earth Syst Sci 11:2173-2180

Hetland EA, Musé P, Simons M, Lin YN, Agram PS, DiCaprio CJ (2012) Multiscale InSAR Time Series (MInTS) analysis of surface deformation. J Geophys Res 117:B02404. doi:10.1029/ 2011JB008731

Hong SY, Shen XH, Song XG, Shan XJ, Liu ZY, Dai YQ, Kang CL, Jing F (2010a) Three-dimensional deformation field caused by the Gaize earthquake by multi-LOS DInSAR measurement technology, IGARSS2010, pp 765-768. ISBN 978-1-4244-9564-1 
Hong SY, Shen XH, Shan XJ, Liu ZR, Dai YQ, Jing F (2010b) The calculation and analysis of the co-seismic deformation field of Yutian $M_{\mathrm{s}} 7.3$ earthquake basing on the ascending and descending orbit ASAR data. Remote Sens Land Resour 4:98-102 (in Chinese with English abstract)

Hooper A (2008) A multi-temporal InSAR method incorporating both persistent scatterer and small baseline approaches. Geophys Res Lett 35(L16):302. doi:10.1029/2008GL03465

Hu J, Li ZW, Zhang L, Ding XL, Zhu JJ, Sun Q, Ding W (2012) Correcting ionospheric effects and monitoring two-dimensional displacement fields with multiple-aperture InSAR technology with application to the Yushu earthquake. Sci Chin 55:1961-1971. doi:10.1007/s11430-012-40509-x (in Chinese with English abstract)

Institute of Geology, China Earthquake Administration (1982) The album of typical satellite imagery of active structures of China. Seismological Press, Beijing (in Chinese)

Jing F, Shen XH, Kang CL, meng QY, Xiong P (2009) Anomalies of outgoing longwave radiation before some medium to large earthquakes. Earthquake 29(4):117-122 (in Chinese with English abstract)

Jing F, Shen XH, Kang CL, Meng QY, Chen Y, Hong SY (2010) Extracting seismic anomalies based on std threshold method using outgoing Longwave radiation data, IGARSS2010, pp 1561-1564

Jing F, Shen XH, Kang CL, Xiong P (2013) Variations of multiparameter observations in atmosphere related to earthquake. Nat Hazard Earth Syst Sci 13:27-33

Jonsson S, Zebker H, Segall P, Amelung F (2002) Fault slip distribution of the 1999, Hector Mine, California, earthquake, estimated from satellite radar and GPS measurements. Bull Seism Soc Am 92(4):1377-1389 Special issue on Hector Mine earthquake

Kang CL (2008) Research on relation between the OLR field change and earthquake activity in Chuan-Dian region of China. Earthquake 28(3):43-48 (in Chinese with English abstract)

Le H, Liu JY, Liu L (2011) A statistical analysis of ionospheric anomalies before 736 M6.0+ earthquakes during 2002-2010. J Geophys Res 116:A02303. doi:10.1029/2010JA015781

Li M, Kang CL, Li ZX, Jing F, Xue Y, Yan W (2010) Abnormal surface latent heat flux prior to the Wenchuan $M_{\mathrm{s}} 8.0$ earthquake. Earthquake 30(3):64-71 (in Chinese with English abstract)

Li YS, Zhang JF, Luo Y, Jiang WL (2012) PSInSAR surface deformation monitoring with high resolution spotlight mode TerraSAR-X image. Wuhan Univ Press Inf Sci Ed 37(12):1452-1455 (in Chinese with English abstract)

Liu YH (2010) Research on surface ruptures in meizoseismal area based on multi-source remote sensing and data platform visualization. $\mathrm{PhD}$ dissertation of Institute of Geology, China Earthquake Administration (in Chinese with English abstract)

Liu DF, Kang CL (2005) Radiation anomalism before Sumatra island M8.7 earthquake. Recent Dev World Seismol 1:37-39 (in Chinese with English abstract)

Liu F, Xin H, Zhang TB, Lu Q, Ren YX (2007a) Series analysis on the ratio for pixels with abnormal brightness temperature increase and its variation before some earthquakes with $M_{\mathrm{s}} \geq 5.0$ in the Taiwan area. Earthq Res Chin 21(4):437-444 (in Chinese with English abstract)

Liu SJ, Wu LX, Li JP, Dong YQ, Ma BD (2007b) Features and mechanisms of the satellite thermal infrared anomaly before Hengchun earthquake in Taiwan region. Sci Technol Rev 25(6):32-37

Liu SJ, Liu X, Ma YT, Wu LX (2012) Microwave radiation anomaly of Yushu earthquake and its mechanism, IGARSS2012, pp 1192-1195

Liu J, Huang JP, Zhang XM, Shen XH (2013) Anomaly extraction method study and earthquake case analysis based on in situ plasma parameters of DEMETER satellite. Acta Seismol Sin 35(1):72-83 (in Chinese with English abstract)
Lu Y (2008) Analysis of the response of middle and upper atmosphere to the acoustic gravity waves from lower atmosphere. Master's thesis of Institute of Geology and Geophysics, Chinese Academy of Sciences (in Chinese with English abstract)

Massonnet DN, Rossi M, Carmona C, Adragna F, Peltzer G, Feigl K, Rabaute T (1993) The displacement field of the landers earthquake mapped by radar interferometry. Nature 364:138-142

Michel R, Avouac JP (1999) Measuring ground displacements from SAR amplitude images: application to the Landers earthquake. Geophys Res Lett 26(7):75-878

Molchanov OA, Hayakaya M, Rafalsky VA (1995) Penetration characteristics of electromagnetic emissions from an underground seismic source into the atmosphere, ionosphere, and magnetosphere. J Geophys Res 100(A2):1691-1712

Ouzounov D, Freund F (2004) Mid-infrared emission prior to strong earthquakes analyzed by remote sensing data. Adv Space Res 33(3):267-273

Parrot M (1995) Use of satellites to detect seismo-electromagnetic effects. Adv Space Res 15(11):27-35

Pulinets SA, Legen'ka AD, Aleksecv VA (1994) Pre-earthquake effects and their possible mechanism in "Dusty and Dirty Plasmas, Noise and Chaos in Space and in the Laboratory". Plenum Publishing, New York

Qiang ZJ, Xu XD, Lin CG (1990) Satellite infrared thermo-anomaly: earthquake imminent precursor. Chin Sci Bull 35(17):1324-1327 (in Chinese with English abstract)

Qiang ZJ, Kong LC, Zheng LZ, Guo MH, Wang GP, Zhao Y (1997) An experimental study on temperature increasing mechanism of satellitic thermo-infrared. Acta Seismol Sin 19(2):197-201 (in Chinese with English abstract)

Qin K, Wu L, De Santis A, He W (2011) Surface latent heat flux anomalies before the $M_{\mathrm{s}} 7.1$ New Zealand earthquake 2010. Chin Sci Bull 56:3273-3280

Qin K, Wu LX, De Santis A, Meng J, Ma WY, Cianchini G (2012) Quasi-synchronous multi-parameter anomalies associated with the 2010-2011 New Zealand earthquake sequence. Nat Hazard Earth Syst Sci 12:1059-1072

Qu CY, Shan XJ, Ma J (2006) Study on the methods for extracting earthquake thermal infrared anomaly. Adv Earth Sci 7(21):699-705 (in Chinese with English abstract)

Qu CY, Shan XJ, Song XG, Zhang GF, Zhang GH, Guo LM (2011) The PSInSAR technique and its application tO the study on crustal deformation of the Haiyuan fault zone. Chin J Geophys 54(4):984-993 (in Chinese with English abstract)

Qu CY, Zhang GF, Shan XJ, Zhang GH, Liu YH, Song XG (2013) Coseismic and postseismic deformation fields of the 2010 Yushu, Qinghai $M_{\mathrm{s}} 7.1$ earthquake and their evolution processes. Chin J Geophys 56(7):2280-2291. doi:10.6038/cjg20130715 (in Chinese with English abstract)

Shan XJ, Zhang GH (2006) An analysis of dynamic evolution of preseismic interferometric deformation fields in seismic area. Seismol Geol 28(3):441-446 (in Chinese with English abstract)

Shan XJ, Ma J, Song XY, Wang C, Liu JH, Zhang GF (2003) Research on characteristics of focal rupture of the ZhangbeiShangyi earthquake by means of deformation field obtained by space borne D-InSAR. Earthq Res Chin 17(2):113-121 (in Chinese with English abstract)

Shan XJ, Liu JH, Ma C (2004) Preliminary analysis on characteristics of coseismic deformation associated with $M_{\mathrm{s}}=8.1$ Western Kunlunshan pass earthquake in 2001. Acta Seismol Sin 26(5):474-480 (in Chinese with English abstract)

Shen X, Wu Y, Shan X (2007) Remote sensing application in earthquake science and general propose for China earthquake satellite project. Int Prog Earthq Sci 8:38-45 (in Chinese with English abstract)

Shen ZK, Sun JB, Zhang PZ, Wan YG, Wang M, Burgmann R, Zeng YH, Gan WJ, Liao H, Wang QL (2009) Slip maxima at fault 
junctions and rupturing of barriers during the 2008 Wenchuan earthquake. Nat Geosci 2:718-724. doi:10.1038/NGEO636

Shen XH, Zhang XM, Wang LW, Chen HR, Wu Y, Yuan SG, Shen JF, Zhao SF, Qian JD, Ding JH (2011) The earthquake-related disturbances in ionosphere and project of the first China seismoelectromagnetic satellite. Earthq Sci 24:639-650

Sorokin VM, Chmyrev VM, Yashchenko AK (2001) Electrodynamic model of the lower atmosphere and the ionosphere coupling. J Atmos Sol Terr Phys 63:1681-1691

Sun LF, Wan WX, Ding F, Mao T (2006) A theoretical model of gravity wave propagation based on the transfer function. Chin $\mathbf{J}$ Geophys 49(4):957-964 (in Chinese with English abstract)

Sun JB, Shi YL, Shen ZK, Xu XW, Liang F (2007a) Parameter inversion of the 1997 Mani earthquake from InSAR co-seismic deformation field based on linear elastic dislocation model-II. Slip distribution inversion. Chin J Geophys 50(5):1390-1397 (in Chinese with English abstract)

Sun L, Wan W, Ding F, Mao T (2007b) Gravity wave propagation in the realistic atmosphere based on a three-dimensional transfer function model. Ann Geophys 25:1979-1986

Sun JB, Shen ZK, Xu XW, Bürgman R (2008) Synthetic normal faulting of the 9 January 2008 Nima (Tibet) earthquake from conventional and along-track SAR interferometry. Geophys Res Lett 35:L22308. doi:10.1029/2008GL035691

Sun J, Johnson KM, Cao Z, Shen Z, Bürgmann R, Xu X (2011) Mechanical constraints on inversion of coseismic geodetic data for fault slip and geometry: example from InSAR observation of the 6 October $2008 M_{\mathrm{w}} 6.3$ Dangxiong-Yangyi (Tibet) earthquake. J Geophys Res 116:B01406. doi:10.1029/2010JB007849

Tronin AA, Hayakawa M, Molchanov OA (2002) Thermal IR satellite data application for earthquake research in Japan and China. Adv Space Res 33(4-5):519-534

Wan YG, Shen ZK, Wang M, Zhang ZS (2008) Coseismic slip distribution of the 2001 Kunlun mountain pass west earthquake constrained using GPS and InSAR data. Chin J Geophys 51(4):1074-1084 (in Chinese with English abstract)

Wang YX, Pan WY, Jin RH, Zhang HQ (2009) Electromagnetic fields in spherical earth-ionosphere excited by SLF/ELF underground horizontal electric sipole. Chin J Radio Sci 24(6):1002-1008 (in Chinese with English abstract)

Wen SY (2011) A study on the brightness temperature background field foundation and the method for extracting anomalies of thermal infrared in seismotectonic area. China University of Petroleum, Dongying (in Chinese)

Wu Y, Qiao XJ, Zhou YY (2005) Preseismic ionospheric TEC anomaly detected by ground-based GPS. J Geodesy Geodyn 25(2):36-40 (in Chinese with English abstract)

Wu LX, Qin K, Liu SJ (2012a) GEOSS-based thermal parameters analysis for earthquake anomaly recognition. Proc IEEE 100(10):2891-2907

Wu LX, Qin K, Liu SJ, De Santis A, Cianchini G (2012b) Importance of lithosphere-coversphere-atmosphere coupling to earthquake anomaly recognition, geoscience and remote sensing symposium (IGARSS), 2012 IEEE International IEEE, pp 3532-3535
Xiong P, Shen XH, Bi YX, Kang CL, Chen LZ, Jing F, Chen Y (2010) Study of outgoing longwave radiation anomalies associated with Haiti earthquake. Nat Hazard Earth Syst Sci 10:2169-2178

$\mathrm{Xu}$ CJ, Wen YM (2008) Nonhomogeneity of the crust from $M_{\mathrm{s}} 7.9$ Manyi (Tibet) earthquake with InSAR observation. Geomat Inf Sci Wuhan Univ 33(8):846-849 (in Chinese with English abstract)

Xu XD, Xu XM, Ma SD (1993) The first trial and some knowledge on the mechanism of the impending earthquake abnormal of the satellite thermal infrared radiation. J Zhejiang Norm Univ 16(3):86-90 (in Chinese with English abstract)

Xu T, Hu YL, Wu J, Li CB, Wu ZS, Suo YC, Feng J (2012) Statistical analysis of seismo-ionospheric perturbation before $14 M_{\mathrm{s}} \geq 7.0$ strong earthquakes in Chinese subcontinent. Chin J Radio Sci 27(3):507-512 (in Chinese with English abstract)

Yang J, Wu Y, Zhou YY (2011) Probe into seismo-ionospheric anomaly of Wenchuan $M_{\mathrm{s}} 8.0$ earthquake based on computerized ionospheric tomography. J Geodesy Geodyn 31(1):9-14 (in Chinese with English abstract)

Yao YB, Chen P, Zhang S, Chen JJ, Yan F, Peng WF (2012) Analysis of pre-earthquake ionospheric anomalies before the global $M=7.0$ + earthquakes in 2010. Nat Hazard Earth Syst Sci 12:575-585

Yu HY, Zhou HJ, Qiao XL (2010) Study on wave propagation of ELF emission anomaly before $M_{\mathrm{s}} 8.0$ Wenchuan earthquake. Acta Seismol Sin 32(6):541-548 (in Chinese with English abstract)

Zebker HA, Rosen PA, Goldstein RM, Gabriel A, Werner CL (1994) On the derivation of coseismic displacement fields using differential radar interferometry: the Landers earthquake. J Geophys Res 99:19617-19634

Zhang HQ, Chen Y, Pan WY (2009a) Fields excited by earthquake ELF/SLF radiator on the ground and in the ionosphere. Chin $\mathrm{J}$ Radio Sci 24(3):432-439 (in Chinese with English abstract)

Zhang XM, Shen XH, Qian JD, Lu L, Chen HR, Ouyang XY (2009b) Advances in the analysis and application of seismo-electromagnetic satellite data in China. Earthquake 29(Supp):34-45 (in Chinese with English abstract)

Zhang GH, Qu CY, Shan XJ, Zhang GF, Song XG, Wang RJ, Li ZH, $\mathrm{Hu}$ JC (2011) The coseismic InSAR measurements of 2008 Yutian earthquake and its inversion for source parameters. Chin J Geophys 54(11):2753-2760. doi:10.3969/j.issn.0001-5733. 2011.11.005 (in Chinese with English abstract)

Zhang X, Shen X, Parrot M, Zeren Z, Ouyang X, Liu J, Qian J, Zhao S, Miao Y (2012) Phenomena of electrostatic perturbations before strong earthquakes (2005-2010) observed on DEMETER. Nat Hazard Earth Syst Sci 12:75-83

Zhao SF, Shen XH, Pan WY, Zhang XM, Liao L (2010) Penetration characteristics of VLF wave from atmosphere into lower ionosphere. Earthq Sci 23(3):275-281

Zhu FY, Wu Y, Zhou YY, Lin J (2010) Statistical analysis of preearthquake ionospheric TEC disturbance. J Geodesy Geodyn 30(5):19-23 (in Chinese with English abstract) 